\title{
Cold Mountain and the Beat Generation of America
}

\author{
Wu Tao \\ Faculty of Foreign Languages and Cultures of Kunming University of Science and Technology, Kunming, China
} (benjaminwalter@163.com)

\begin{abstract}
Hanshan, a Tang zen monk of China, has been admired as a spiritual idol by the Beat Generation of America. Hanshan's views of nature, society, and especially of self, as reflected in Hanshan's poems, echo with views of the Beat Generation. The Hanshan spirit that permits Hanshan's poems is in accordance with the world perspective of rebellious youth of modern America after the Second World War. Hanshan and his poems are therefore warmly received in America.
\end{abstract}

Keywords - Hanshan, the Beat Generation, view of nature, view of society, view of self

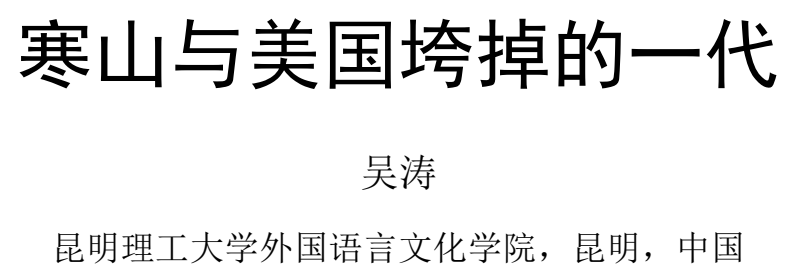

摘 要 中国唐代禅僧寒山被美国垮掉的一代尊为精神偶像。寒山诗在自然观、社会观, 特别是自我观上与美国垮掉一代极为契 合。其诗歌中体现出的寒山精神暗合二战后的现代美国叛逆年轻人对世界的看法, 在美国广受赞誉。

关键词 寒山, 垮掉的一代, 自然观, 社会观, 自我观

寒山诗第三零五首云: 有人笑我诗, 我诗合典雅。不 烦郑氏笺, 岂用毛公解。不恨会人稀, 只为知音寡。若遣 趁宫商, 余病莫能罢。忽遇明眼人, 即自流天下。(1) 寒山 究竟何许人也, 何以认为自己的诗作尽管多被人笑, 被指 为大有毛病, 却终有流传天下的一日? 与寒山相关的记载 皆非信史。据说, 寒山生活在中国唐代, 因隐居于浙江天 台山寒岩一地, 被称作寒山子, 是一个状若疯癫的僧人, 与其游伴拾得纵情山水间, 行踪飘忽不定, 仅有随意丵刻 于岩壁、树叶, 或是人家屋梁的三百余首诗作流传下来。 这样一个疯僧人, 作的又是充满 “不雅” 俗语的白话诗, 一向被中国主流文学界认为是不入流的小道, 比起同为唐 时的李白、杜甫, 名气大有不如。但寒山诗自有其魔力, 自唐时起，他的诗广被文人当做拟作、效法和唱和的底本， 以致竟形成了所谓的 “寒山体”, 其中不乏名人之作, 如王 安石有《拟寒山拾得二十首》, 苏轻亦有 “拟寒山诗八首” (2)。寒山使用白话做诗, 这在唐代是极少有的, 再加上其 诗作对社会的黑暗多有批判, 表达了对劳苦人民的同情, 在进入二十世纪后, 他被誉为白话文运动的先锋。尽管如 此, 总的来说寒山是个游离于中国主流文学之外的人物,
在中国远远谈不上家喻户晓。

赤松子的寒山诗英译本中有这样的评论, “如果中国的 文学评论家要为自己国家的过去最伟大诗人举行一次茶会 的话, 寒山可能不在众多被邀请诗人之列。然而受邀的那 些诗人却与中国的庙宇和祭坛无缘, 可寒山的画像却能被 供奉于众多神仙与菩萨当中。” [1] 寒山在中国可能名声不 显, 但在大西洋彼岸的美国却是个比诗仙李白、诗圣杜甫 更让美国人感到亲切的中国唐代诗人。寒山诗跨越了时间 和空间的阻隔, 消揖了文化传统相异的隔膜, 风靡了无数 他乡异客。寒山本人更是被美国垮掉的一代尊为精神偶像, 其诗歌在嬉皮运动中被美国最敏锐的叛逆知识分子视为指 引方向的东方经典。

垮掉的一代是二十世纪五、六十年代主要流行于美国 的重要的现代主义文学思潮, 既是一种社会、文化运动, 又指一群意趣相投, 对二战后的现代西方社会充满反抗情 绪的作家、思想家和运动家。寒山诗进入美国垮掉一代的 文人圈子多得一人之力, 此人是被称为 “美国寒山” 的美 国深层生态学桂冠诗人盖瑞-史耐德（Gary Snyder, 1930－）。史耐德自幼酷爱中国文化，对中国古代文化中天 
人合一的和谐自然观和禅学思想尤其感兴趣。在导师陈世 骧教授推荐下, 史耐德开始研读禅僧寒山的作品, 并着手 进行翻译, 在三百余首寒山诗中精选了二十四首译为英文。 正是这二十四首寒山诗让受垮掉的一代精神影响的美国年 轻人爱上了寒山。1955 年 10 月 13 日是个值得纪念的日子, 从这一天开始, 寒山被和美国垮掉的一代紧密联系在了一 起。这一天, 史耐德及一批垮掉一代的文人突然间入了公 众的视野。年仅 25 岁的史耐德在六画廊诗歌朗诵会上诵读 了他翻译的几首寒山诗, 获得了热烈的反响。1958 年, 史 耐德在宣传垮掉的一代思想的刊物《常青评论》的秋季号 第二卷第 6 期上发表了二十四首寒山诗英译。这些寒山诗 英译后来又被收录于加州大学学者托马斯・帕金森编辑的 研究垮掉一代的核心材料《“垮掉一代” 文丛》中, 至今仍 是最具影响力的寒山诗英译。史耐德被称为 “美国寒山” 并不仅仅由于他翻译的寒山诗, 在生活中他也处处追随着 这位东方精神导师的脚步, 不仅亲赴日本系统地修习禅道, 甚至还曾多次幽居于美国山林中做一个伐木工人, 一边参 禅一边进行诗歌创作。

另一个对寒山诗在美国的流行多有襄助的 “明眼人” 是垮掉的一代的灵魂人物, 杰克・凯鲁亚克 (Jack Keroac, 1922-1969)。1955 到 1956 年间, 凯鲁亚克曾同友人史耐德 一道隐居在加利福尼亚州米尔谷的林中小屋里。受这位“美 国寒山” 的影响, 凯鲁亚克将其 1958 年出版的自传性小说 《达摩流浪者》(Dharma Bums) 题献给寒山, 并在书中多次 谈到寒山及寒山的诗作。小说的末尾这样写道, “忽然间, 我仿佛看到那个邋逷得无法想象的中国流浪汉, 就站在前 面, 就站在雾里, 皱纹纵横的脸上透着无法言诠的幽默表 情。那并不是真实生活中的贾菲, 不是背着背包、学佛和 在派对上纵酒狂欢的贾菲, 而是比现实更真实的那个贾菲, 我梦想中的贾菲。” [2] 中国唐代诗僧寒山与二十世纪美国 西岸诗人史耐德被凯鲁亚克糅合塑造成小说主人公心目中 的英雄贾菲, 指引主人公最终在孤凉峰上获得了精神顿悟, 西方上帝的爱与东方佛祖的慈悲融化了流浪者的灵魂, 自 此获得永恒的年轻与生存的意义。《达摩流浪者》掀起了旷 日持久的寒山热，寒山诗成了美国年轻人的必读。

美国二十世纪五、六十年代的物质繁荣实际只是一翟 即破的浮华梦, 是以政治迫害、冷战高压、原子恐怖、思 想控制、精神异化之危机等为代价的。物质消费导致精神 自我的沦丧, 专制泿灭了自由, 正统的道德和社会规范抹 杀了人的个性, 使之模式化。一切都威胁着人的精神存在。 敏感的垮掉一代的年轻思想者们是一群不惜以离经叛道的 自我邽落来进行反抗的抗争者, 一直因为他们放浪形骸的 表象遭到人们的误解和错判。事实上, 深受东方思想影响 的垮掉的一代在对待自然、对待社会和对待自我的态度上
都能给西方资本主义世界许多深刻的启示。寒山诗被美国 垮掉的一代引为经典, 受到现代美国年轻人的喜爱与推崇 是诸多因素相互交织的结果。一是在日本铃木大拙等人将 禅学推广到西方世界的过程中得到推波助澜, 被急于从东 方寻求精神指引的垮掉的一代当成东方智慧的来源之一; 二是寒山诗语言浅俗、易晓易喻, 与诗坛追求精致典雅的 陈规相对立, 追求朴野骇俗的效果, 与垮掉的一代随意浅 白、直抒胸臆的创作风格和黑色幽默的风骨相投合。三是 寒山诗中体现出的寒山精神, 尤其是寒山的自然观、社会 观和自我观与美国垮掉一代的精神态度极为契合, 互为跨 时空的千古知音。这也是寒山与垮掉一代解不开的缘分最 深刻的内在原因。寒山将普通的人情世态纳入诗歌中。反 映了下层民众发自内心的苦涩于彷得。这类诗中也不乏反 映自然生态、人世警思甚至忧国忧民之作。［3］映照着美 国二十世纪垮掉一代年轻人的苦涩与彷得, 叛逆的年轻思 想者们从寒山诗中得到了关于人与自然、人与人、人与自 身关系的东方启发。

自然观是人们对自然界的根本看法, 先天就带有某一 文化的特点。中国与西方的自然观向来有极大差别, 体现 了东方文化与西方文化各自的特点。在典型的西方自然观 中, 人与自然是对立的, 自然是人类对抗、征服的对象。 这种对立在现代工业文明背景下达到了极致, 对工业进步 带来的巨大利益的追求让大自然被短视的人类破坏得满目 疮痍, 人们追求物质带来的满足, 遗忘了大自然对人心的 治愈。而中国自古就崇尚和顺应自然, 不违天命, 把人与 自然看作是和谐的一体, 视天人合一为最高的境界。总体 来说, 中国古人对自然始终抱有一种神秘感, 认为人在自 然中方能澄清自己的内心。东方文化中这种古已有之的对 自然的神秘性的近似于宗教崇拜的认识, 与西方浪漫主义 的自然观不谋而合。垮掉的一代的作家向来被认为承接了 浪漫主义的衣钵。垮掉派最年轻的诗人格雷高里・柯尔索 (Gregory Corso, 1930-2001) 崇拜英国浪漫派诗人雪莱。“嚎 叫” 诗人阿伦・金斯伯格 (Allen Ginsberg, 1926-1997) 的诗 歌创作深受浪漫诗风, 特别是诗人布莱克的影响。出于对 工业文明的唾弃和对自然原始的美好生活的憧憬，垮掉的 一代的浪漫主义情怀让他们极容易受寒山诗里描述的人在 自然中的自在存在的感染。寒山诗中有很多写尽亲近自然 之乐的诗句, 如 “入夜歌明月, 侵晨舞白云”、“微风吹幽 松, 近听声愈好”、“秋到任他林落叶, 春来从你树开花。 三界横眠无一事, 明月清风是我家”、“粤自居寒山, 曾经 几万载。任运遁林泉, 栖迟观自在。寒岩人不到, 白云常 叆动逮。细草作卧裖, 青天为被盖。快活枕石头, 天地任变 改”、“登陟寒山道, 寒山路不穷。溪长石磊磊, 润阔草蒙 蒙。苔滑非关雨, 松鸣不假风。谁能超世累, 共坐白云中” 
等。禅僧寒山的诗句将诗境与禅境交融于自然物象中。禅 家极重自然, 自然山水是他们的栖隐之处, 禅意泛化的自 然万象是他们参悟的对象。在垮掉的一代的文学作品中, 自然也是精神洗涤的最佳场所, 是主人公人生顿悟的必要 条件。只有在美丽自然风光的怀抱中, 被现代社会的污染 茶毒的心灵才开始敞开, 所有的不愉快似乎都消弭了, 灵 魂真切地感受到生命的美好和存在的意义。垮掉的一代普 遍认为现代美国需要的是一种与荒野共生的和谐文明。寒 山之所以是精神偶像, 是因为他抽离世俗、走向荒野的举 动深深触动了垮掉一代的灵魂。

社会观既是对社会的看法, 更是对自身在社会中所处 境地及人与人之间共存关系的理解。寒山的社会观念据其 诗歌中的体现来看是肉身超然出世和精神关切入世的结 合。寒山诗中表达道家出世思想的句子比比皆是, 如: “谁 能超世累, 共坐白云中”、“我居山, 勿人识。白云中, 常 叔叔”、“寄语钟鼎家, 虚名定无益”、“谁知出尘俗, 驭上 寒山南”、 “更观尘世外, 梦境复何为” 等。但寒山诗里也 不乏对凡俗尘世的描写, 多有得道者的劝化之语, 主要可 看那些以 “我劝世间人” 开篇的诗作。寒山诗对尘世现实 之苦也多有刻画, 其中最典型的是 “驱马度荒城, 荒城动 客情。高低旧雉堞, 大小古坟莹。自振孤蓬影, 长凝拱木 声。所咩皆俗骨, 仙史更无名。” 描写出的是一个鬼气森森, 逃脱无望的现实牢笼, 与西方现代社会的绝望现实可堪一 比。寒山的社会观在史耐德选译的二十四首诗中体现得较 为集中。史耐德从美国现代社会现实出发对诗序进行了繁 费苦心的调整编排, 可以看到道家的出世思想与儒家 “穷 则独善其身, 达则兼济天下” 的融合。此方面最值得关注 的一首寒山诗是 “时人见寒山, 各谓是风颠。貌不起人目, 身唯布装缠。我语他不会, 他语我不言。为报往来者, 可 来向寒山。” 该诗被史耐德安排在组诗末尾, 起到画龙点睛 之效, 从中明确的表达出了寒山 (包括史耐德自己) 以诗 渡人的心志。“在美国青年的眼中, 寒山成为理想的禅癫和 巨大智慧的禅宗流浪汉。” [4] 垮掉一代的年轻人在西方现 代社会中也如寒山一般, 以疯狂颠倒为外相, 内在却精神 清醒地认识到了所处社会的危机四伏。无论是在寒山诗中 的尘世还是在现代西方社会, 现实都是丑恶而残酷的。有 此意识的寒山选择了隐居自然山水间, 垮掉的一代则选择 了自我放逐和流浪。

自我观可以视为是探索自身存在的某种发现, 是对自 身的认识和定位, 可以从个人的生活方式, 愿望、追求中 看出一二。从寒山的一些诗句中可以推测出寒山本是一个 儒生, 对仕途科举未必没有过幻想, 后才意识到此路不通, 且觉得世俗教诲与自己的内心极度违背, 才择居寒岩, 苦 修自身。寒山抛弃了自己的儒士身份, 选择做一个不合礼
制的疯癫僧人, 表现出的是对压抑现实和无用传统的叛逆, 这与垮掉的一代背弃基督教文化道德传统选择醉生梦死的 放荡生活有一定相似性。垮掉的一代是用自己独特的、惊 世骇俗的方式在所有领域进行着史无前例的反叛, 反对着 资产阶级道德规范和市侩文化。垮掉的一代以乘张畸怪的 行为将自己从早已深恶痛绝的主流社会中放逐, 踏上了一 条流浪者之路, 表面上是不愿合群、拒绝安定, 实际上是 在寻找精神家园的路上走得太远。寒山是一个隐士, 垮掉 的一代则都是流浪者, 殊途却同归, 都是个人一种精神追 寻的尝试。寒山于隐居中得到了在苦痛人世间继续生存的 大智慧, 并在其诗歌中书写出来, 垮掉的一代正是深深理 解了这种大智慧, 才完成了对寒山诗的精神认同并将寒山 引为流浪之路上的精神导师的。当然, 这种东方的隐逸智 慧, 未必真是拯救自我的灵丹妙药, 或许不过是一种获得 拯救的幻觉而已。但寒山这类禅林诗人在月下欢乐的梦行, 对垮掉派来说, 与更神圣的典籍同样重要。如果任幻觉自 由驰骋, 他们真的就只生活在幻觉之中。[5] 这已经足可 慰藉心灵了。

正是佛学禅宗为垮掉的一代提供了一方精神探寻和栖 息的家园, 中国博大精深的儒道思想令许多垮掉作家折服、 沉迷, 中国古典诗歌、山水画等所独具的艺术精神和艺术 手法更是深深影响了垮掉诗人, 使他们的诗歌具有浓郁的 东方意蕴。[6] 寒山诗内容驳杂, 可以说儒、释、道三家 的思想都交汇其中, 而佛教内涵是其最突出的思想特征, 其自然观、社会观和自我观也多受佛教、道教, 乃至儒家思 想的影响。寒山自己借诗言说: 禅不在诗中, 而在心中。 寒山的生平事迹已不可考, 纵使凭借诗句试做推断, 看到 的也是传说中玄妙怪奇的禅家原型，早已脱了凡俗之人的 意味。可以说, 作为凡人的寒山是不存于世的, 而禅僧寒 山的形象则鲜活灵动地存在于那三百余首作者未明的寒山 诗中, 感召着读者心中自有的寒山精神。在中国, 在西方, 在美国，在自我放逐的嬉皮士心中，都有一个追求精神家 园的寒山存在。正如史耐德所说: “他们（寒山和拾得）变 成了神仙, 现今人们有时候还可以在贫民区、果园、流浪 者聚居的从林和伐木工人的帐篷里与他们不期而遇。” [3]

注释:

(1)文中所引寒山诗皆出自项楚编著中华书局 2000 年 版《寒山诗注 (附拾得诗注)》。

(2) 见《东坡全集》卷二十三，《文渊阁四序全书》1107 册; 《次韵定慧饮长老见寄八首》。

本文系国家留学基金项目资助(CSC NO.201308530020) 阶段性研究成果。昆明理工大学校级翻译研究学科方向团 队资助阶段性研究成果。 


\section{参考文献(References)}

[1] Porter, Bill, The Collected Songs of Cold Mountain, Copper Canyon Press, 2000.

[2] Keroac, Jack, The Dharma Bums, Shanghai: Shanghai Translation Publishing House, 2008.

[3] Hu, Anjiang, Hanshan Poems: Text Travel and Construction of
Literary Canon, Beijing: Tsinghua University Press, 2011.

[4] Zhong, Ling, Snyder and Chinese Culture, Beijing: Capital Normal University Press, 2006.

[5] Li, Si, The Beat Generation, Haikou: Hainan Publishing House, 1996.

[6] He, Li, "Literary Thoughts on Beat Generation," Journal of Xuzhou Education College, Vol.3, pp.107, 2003. 